\title{
Effect of counseling by paraprofessionals on depression, anxiety, somatization, and functioning in Indonesian torture survivors
}

\author{
Deborah Larson-Stoa, PhD*, Gerard A. Jacobs, PhD*, Abraham Jonathan, BA**, \\ Bhava Poudyal, MA**
}

\begin{abstract}
The Indonesian population has faced political violence, victimization, and torture throughout the last 70 years. Due to the scarcity of mental health professionals in many low and middle-income countries, counseling programs are increasingly utilizing paraprofessionals to provide support to the affected population as a strategy of task shifting. In this article, we would like to examine the effectiveness of counseling services provided by such trained paraprofessionals. This study was part of program evaluation to determine whether the participants (torture survivors) improved after counseling services provided by trained paraprofessionals in Indonesia. Local communities were invited to join the psychosocial program created and implemented by an NGO in 2005. The 178 participants were recruited from Jakarta, Papua, and Aceh, Indonesia for the program, which aimed to help survivors of violence suffering from "heavy hearts." The intervention lasted three months, and the follow-up intake was conducted after four months.
\end{abstract}

\footnotetext{
^) Disaster Mental Health Institute at University of South Dakota

${ }^{\star \star}$ ) International Catholic Migration Commission (ICMC), Indonesia
}

Correspondence to: bhavapoudyal@gmail.com
The results indicated the participants' anxiety symptoms, depressive symptoms, somatic symptoms, and functioning improved from the intake to the follow-up.

The program appeared to have been effective in reducing the participants' symptoms and impairment in functioning. This indicates that in countries where there is a scarcity of mental health professionals, working with paraprofessionals has the potential to help survivors of torture and violence.

Keywords: Paraprofessionals, task shifting, counseling, support groups, depression, anxiety, somatic, functioning, torture survivors

\section{Introduction}

According to Amnesty International, ${ }^{1}$ approximately 101 countries continued to use torture and ill treatment in 2011. Vesti and Kastrup ${ }^{2}$ considered torture to be different from other traumatic events because of the total and complete control the torturer attempts to exert over the victims. The general purpose of torture is to break down the will of the victim and destroy the individual's spirit, individuality, ${ }^{2-4}$ personality and judgment. ${ }^{3,5}$ It is a direct attack on the individual, and the biggest challenge for the victims, aside from surviving, is retaining their spirit and personality. ${ }^{5}$ 


\section{Effects of torture}

Torture survivors are more likely than other violence-exposed populations to experience posttraumatic stress disorder (PTSD) symptoms, major depression, and high levels of anxiety; all of which have an impact on how they function and their quality of life. ${ }^{6-13}$ Somatic complaints and chronic pain are the most common physical consequences of torture. ${ }^{7-9,11-14}$ These psychological and physical sequelae of torture are considered to be chronic, and greatly affect the quality of life of the survivors. ${ }^{8-10,15}$

Research indicated that experiencing torture alone did not appear to lead to the development of depression and PTSD. ${ }^{13}, 16$, ${ }^{17}$ The presence of chronic injuries from torture, perceived distress, and the unpredictable and uncontrollable nature of torture, resulted in the development of depression and PTSD. ${ }^{13,16,17}$

\section{Therapy for survivors of torture}

In treating survivors of torture, there are three stages of therapy: Establishment of Safety and Trust; Reconstruction; and Reconnection. ${ }^{3,5,18}$ The Establishment of Safety and Trust is the first and most critical stage. $3,5,8,18$

This stage begins with the establishment of a rapport and confidence in the therapist and gradually develops to a point where the client feels safe in the therapeutic environment. ${ }^{3,5,18,19}$

The first phase of therapy typically necessitates a supportive, validating and nonjudgmental atmosphere in order for the survivor to feel safe and establish trust in the therapist. $3,5,8,18,19$ Survivors of torture commonly have difficulty establishing trusting relationships following their experiences.

In the second phase of therapy: Reconstruction, the survivor reveals the traumatic event narrative within the safe and supportive therapeutic environment. ${ }^{3,5,18}$ The foundation of the Reconstruction phase is cognitive restructuring of the torture experience(s) and the resulting shifts in core beliefs and schemata. ${ }^{3,5}$

In the third phase in therapy: Reconnection, survivors find new meaning in their lives and begin to find value in their sense of identity. This increases their openness to new experiences and ability to reconnect with others. ${ }^{3,5,18}$

Mental health treatment of torture survivors became a growing concern in the 1970s. ${ }^{18}$ In the last 15 years, treatments for torture survivors that have become accepted are cognitive-behavioral therapy (i.e. exposure therapies), cognitive processing therapy, other behavioral, supportive and group therapies, ${ }^{5,18-20}$ and narrative exposure therapy (NET), which has shown potential positive impact. $^{21}$

The types of therapy available to torture survivors that have been rigorously studied are those provided by trained and licensed mental health professionals. However, the majority of the countries where these torture survivors come from, or reside in, are low and middle-income countries (LAMIC), where despite the larger burden of mental health, there is a scarcity of professional mental health care providers. For example, Tol et $\mathrm{al}^{22}$ conducted a meta-analysis on the types of services provided in these countries during emergencies. Specialized services, those provided by psychiatrists, psychologists, psychiatric nurses, etc., accounted for only $28.1 \%$ of all services provided. Non-specialized services, those provided by health care workers and community members, accounted for $62.5 \%$ of the services provided.

The World Health Organization (WHO) Mental Health Atlas shows that in Indonesia there are 0.01 psychiatrists per 100,000 
population; the number of psychologists is unknown. ${ }^{23}$ This disparity between the burden of mental health and the severe lack of mental health professionals in LAMIC has forced international mental health professionals to consider Task Shifting as a strategy. ${ }^{24,25}$ Task Shifting, as the phrase implies, means that in contexts where there is a scarcity of mental health professionals, training and supervision is provided to interested people without a mental health background to enable them to provide the care needed under the supervision of mental health professionals. ${ }^{24,25}$ In doing so, the mental health professionals need to simplify theories and take practical elements of different therapies to train these "paraprofessionals". They could then become the front line service providers under the guidance and supervision of mental health professionals.

\section{The program}

The program that is the focus of this study, Survivors of Torture (SOT), was created and implemented by the International Catholic Migration Commission (ICMC) in 2005.

Due to the lack of trained mental health professionals in the targeted geographical areas, the ICMC recruited "paraprofessionals" locally and trained and supervised them in individual and group counseling skills. The recruited paraprofessionals had a college degree in a different field of study, but were interested in working as "helpers".

The training focused on basic counseling skills, client centered problem solving skills, psycho-education, relaxation techniques, group facilitation skills (for support groups) common mental health problems and the mental health challenges facing torture survivors. The paraprofessionals functioned as the direct service providers in their respective districts under the supervision of ICMC staff (psychologists).
The data collected in this study were obtained for program monitoring that had been integrated into the program in order to monitor client improvement. The SOT data collected by ICMC staff were analyzed by the Disaster Mental Health Institute (DMHI) at the University of South Dakota (USD).

The goal of this study was to determine whether the participants (torture survivors) improved after counseling with paraprofessionals. The hypothesis to be tested was that anxiety, depression, and somatic symptoms would decrease from Time 1 to Time 2, and level of functioning would improve from Time 1 to Time 2 .

\section{Methods}

Participants

The participants of this study were torture survivors residing in Aceh, Jakarta and Papua in Indonesia. The program targeted Aceh Besar in Aceh and Demta in Papua due to the conflicts in those locations, and also focused on Jakarta due to the high population of torture survivors residing there.

The program was open to all adult torture victims in the targeted districts. In Aceh and Jakarta, female survivors were more interested in participating than male survivors and were also willing to participate in support groups. Male survivors participated in Papua (though it was also open to female survivors).

This may have been due to Papua's strict patriarchal society, or because it is mostly men that are accused of being a member or supporter of the OPM (Organisasi Papua Merdeka, which stands for: Free Papua movement), an alleged separatist movement in Papua. The men preferred individual counseling because of their fear of military raids. They did not believe it would be safe to 
meet in groups because it could arouse suspicion.

Local communities in the targeted districts were educated on the effects of life stressors, and how stressors affect the mind, body, relationships, and behavior through awareness raising sessions.

The local counselors (paraprofessionals) spoke with the community leaders, religious leaders, other local NGOs and health service centers to promote the program. The residents who were known to be suffering from "heavy hearts" as a result of torture experiences were referred by NGOs, the village leaders and other community/ religious leaders. Any resident who expressed an interest in the program was allowed to participate.

For those suffering from psychosis, the paraprofessionals were trained to encourage the family to take the person to a hospital. They were not included in the program because the program did not have the capacity to administer psychotropic medications due to the limitations of both human and financial resources. The residents were informed that the SOT program was a talking group for individuals with "heavy hearts," and interested clients were invited to join the program.

It is important to note that those suffering from psychosis were not referred to the program; perhaps because psychosis does not fall under the local construct of "heavy heart", which tends to capture the comorbidity of depression and anxiety.

The aim of the program was to reduce the psychological effects of torture for the survivors, their families, and witnesses of torture in the general community. 215 individuals joined the program, 37 individuals were not available for a follow-up interview, therefore 178 participants $(82.8 \%)$ were included in the study.
The participants had experienced a long list of traumatic events, but the most common were: Beatings, loss of house/farm (mostly as a result of arson), the death of a family member, being taken captive, torture, being forced to watch violence be inflicted on their family/others, rape and being intimidated/threatened. The data analyzed in this study were collected as part of regular program evaluation in order to monitor client improvement and ensure the efficaciousness of the intervention.

\section{Measures}

Three psychological measures were used to collect data for this study: The Hopkins Symptoms Checklist-25 (HSCL-25); the Current Level of Functioning Questionnaire and the Seven Common Somatic Symptoms List.

The Hopkins Symptoms Checklist-25 (HSCL-25) The HSCL-25 is a screening tool which measures symptoms of anxiety and depression. The HSCL-25 consists of 10 questions, which measure anxiety and 15 questions which measure depressive symptoms. The HSCL-25 has not been standardized in the Indonesian language, though it has a reported inter-rater reliability for Indochinese populations of .98 for the entire scale. ${ }^{26}$ The test-retest reliability for the entire scale is reported as .89 and .82 respectively for depression and anxiety subscales. ${ }^{26}$ The HSCL-25 has a high content validity. ${ }^{27}$

The HSCL-25 was translated into Bahasa Indonesia, the national language of Indonesia, and translated back to English. This back-translation process was completed twice and the resulting instrument was piloted before being used in the SOT program. Each of the three locations participating in the program (Aceh, Papua 
and Jakarta) has their own dialect, though the local people understand Bahasa Indonesia, including the elderly population. All interviews were conducted by locally trained paraprofessionals who were fluent in Bahasa Indonesia. The paraprofessionals were also trained to repeat questions in the local dialects if the participants did not initially understand the question.

\section{Current Level of Functioning Questionnaire}

The Current Level of Functioning Questionnaire was developed by one of the co-authors Bhava Poudyal, for specific use with waraffected populations in Sierra Leone and Liberia. The questionnaire was developed following three focus group discussions for men and women with refugees from Sierra Leone and Liberia living in Guinea. The focus groups were asked, "How do you know a woman or man is functioning well in your community?" The responses from the focus groups were free listed, and a group of locally trained counselors categorized the different tasks. For example, men would fix the roof or a fence, and women would cook and clean for the household. In the questionnaire this became, "Did you have difficulties doing domestic work around the house because you were not feeling well?"

The Current Level of Functioning Questionnaire consists of ten questions. The Indonesian paraprofessionals thought the questionnaire was more relevant in their cultural context in comparison to WHODAS II, thus the questionnaire was translated into Bahasa Indonesia, and back-translated in order to check for consistencies in the translation. The questionnaire was piloted and yielded an internal reliability of 0.8. It was piloted in Jakarta before it was used in all three locations (Aceh, Papua and Jakarta) for the SOT program. As with the HSCL-25, the interviews were conducted by local trained paraprofessionals who were fluent in Bahasa Indonesia.

\section{Seven Common Somatic Symptoms List}

The Seven Common Somatic Symptoms List is a brief list of the most common somatic symptoms among individuals. It is adapted from the Bradford Somatic Inventory (BSI). ${ }^{28}$ It was used in the SOT program in order to measure the participants' level of somatization. For the purpose of the SOT program, the participants were asked how much they were bothered by the following somatic symptoms in the last seven days: Headaches, faintness or dizziness, pain in heart or chest, pain in lower back, soreness of muscles, numbness or tingling in parts of your body and feeling weak in parts of their bodies.

\section{Procedure}

Torture survivors in the targeted districts in Jakarta, Papua, and Aceh, Indonesia were introduced to the program and encouraged to participate if they had a "heavy heart." Female survivors participated in Jakarta and Aceh, while male survivors participated in Papua.

The trained paraprofessionals conducted the first intake (T1) using the HSCL-25, Current Level of Functioning Questionnaire and the Seven Common Somatic Symptoms List. The intervention lasted approximately three months. The male participants in Papua were given individual sessions of supportive counseling with locally trained counselors, while the female participants in Jakarta and Aceh were included in support groups with locally trained counselors.

The participants in Papua received individual counseling in order to protect the confidentiality and safety of the participants as the conflict was ongoing. The follow-up intake (T2) using the HSCL-25, the Current Level of Functioning Questionnaire and the 
Seven Common Somatic Symptoms List was conducted four months after an individual finished the program. The follow up intake was carried out by a different paraprofessional than the one that provided the therapeutic services.

\section{The interventions}

The group intervention was formatted for eight support group sessions. It focused on aiding the participants in expressing their problems, finding their natural coping strategies, helping them to manage their problems, and motivating and encouraging them to support each other both within the group settings and outside the formal sessions. Suggestions for coping and problem-solving, as well as support were provided by group members. The themes discussed in group were generated during the first session by the group members. The themes discussed were: Fear, anger/frustration, sadness, loss of hope and lack of motivation.

The individual sessions conducted with men aimed at providing emotional support through empathic listening, normalization of symptoms, and teaching relaxation and communication skills.

The counselors aided the participants in developing and accomplishing realistic goals through client centered problem management counseling when they encountered challenging situations in their lives. They also aided the participants in managing the emotional impact of problem situations when they could not be changed. For example, for problems that did not have solutions (i.e., the loss of family members). The focus was on managing emotions and accessing coping skills. There was no fixed number of individual sessions, which ranged from two to ten.

\section{Results}

The hypothesis that anxiety, depression, somatic symptoms and level of functioning would improve from Time 1 (T1) to Time 2 (T2), was analyzed using repeated measures multivariate analyses of variance (MANOVAs). As women in Jakarta and Aceh received group therapy and men in Papua received individual therapy, the data from the male participants were analyzed separately from that of the female participants.

In general, female participants in Aceh had higher levels of somatic and anxiety symptoms at $\mathrm{T} 1$, but achieved low symptomatology and impairment similar to female participants treated in Jakarta following group therapy. Male participants in Papua consistently improved in symptomatology and impairment following individual therapy, but those treated in this location did not improve as much as female participants in Jakarta and Aceh (see Table 1 and Figures 1 to 4).

The repeated measures MANOVA for female participants in Jakarta and Aceh, with time and location as independent variables, indicated a significant effect for Time $(\mathrm{F}=$ $47.15, \mathrm{p}=.000)$ and Location $(\mathrm{F}=6.17, \mathrm{p}$ $=.000)$. The interaction between time and treatment factors was significant $(\mathrm{F}=2.66, \mathrm{p}$

Table 1: Percent improvement of symptomatology by location

\begin{tabular}{lllll}
\hline Location & $\begin{array}{l}\text { \% Somatic } \\
\text { improvement }\end{array}$ & $\begin{array}{l}\text { \% Anxiety } \\
\text { improvement }\end{array}$ & $\begin{array}{l}\text { \% Depressive } \\
\text { improvement }\end{array}$ & $\begin{array}{l}\text { \% Functioning } \\
\text { improvement }\end{array}$ \\
\hline Jakarta & 65.9 & 59.9 & 65.5 & 78.0 \\
Aceh & 65.6 & 68.7 & 66.4 & 72.1 \\
Papua & 34.8 & 25.4 & 23.1 & 22.2 \\
\hline
\end{tabular}


$=.038)$, which indicated that the amount of change from $\mathrm{T} 1$ to $\mathrm{T} 2$ is related to the location of participants (see Table 2).

The univariate analysis of Time indicated significant effects for Somatic symptoms $(F=125.88, p=.000)$, Anxiety symptoms $(F=90.69, p=.000)$, Depressive symptoms $(F=102.48, p=.000)$, and Functioning $(F=66.22, p=.000)$. The analysis indicated improvement over time for all measured symptoms. Similarly, the univariate analysis of the interaction between Time and Location was significant for Anxiety symptoms $(F=4.29, p=.041)$. The interactions were not significant for Somatic symptoms $(F=2.09, p=.151)$, Depressive symptoms $(F=0.12, p=.732)$, and Functioning $(F=2.45, p=.121)$ (see Table 3$)$. These results indicated that the amount of change in Anxiety symptoms over time was significantly impacted by the location in which the participants resided.

The analysis of between-subjects effects for location was significant for somatic symptoms $(\mathrm{F}=7.56, \mathrm{p}=.008)$, Anxiety symptoms $(\mathrm{F}=5.83, \mathrm{p}=.018)$, Depressive symptoms $(\mathrm{F}=0.72, \mathrm{p}=.399)$, and Functioning $(\mathrm{F}=3.30, \mathrm{p}=.073)$ (see Table 4). This indicates that the extent of the change in the levels of symptoms and impairment were significantly different depending on the location in which the participants resided.

The repeated measures MANOVA for male participants in Papua, with time as independent variable, indicated a significant effect for Time $(F=8.488, p=.000)$. The univariate analysis of time indicated significant effects for somatic symptoms $(F=$ 30.34, $p=.000)$, Anxiety symptoms $(F=$ $10.45, p=.002)$, Depressive symptoms $(F=$ 9.83, $p=.003)$, and Functioning $(F=6.65$, $p=.013$ ) (see Table 5). The analysis indicated improvement over time for all measured symptoms in the Papua participants.
Table 2: MANOVA for Fakarta and Aceh

\begin{tabular}{lll}
\hline Variable & F & $\mathbf{p}$ \\
\hline Location & 6.17 & .000 \\
Time & 47.15 & .000 \\
Time & 2.66 & .038 \\
\hline
\end{tabular}

Table 3: Univariate analysis for fakarta and Aceh

\begin{tabular}{|c|c|c|}
\hline Effect of time on DV & $\mathbf{F}$ & $\mathbf{p}$ \\
\hline Somatic & 125.88 & .000 \\
\hline Anxiety & 90.69 & .000 \\
\hline Depressive & 102.48 & .000 \\
\hline Functioning & 66.22 & .000 \\
\hline $\begin{array}{l}\text { Effect of time }{ }^{\star} \text { location } \\
\text { on DV }\end{array}$ & $\mathbf{F}$ & $\mathbf{p}$ \\
\hline Somatic & 2.09 & .151 \\
\hline Anxiety & 4.29 & .041 \\
\hline Depressive & .12 & .732 \\
\hline Functioning & 2.45 & .121 \\
\hline
\end{tabular}

Table 4: Between subjects effects for location

\begin{tabular}{lll}
\hline Variable & F & p \\
\hline Somatic & 7.56 & .008 \\
Anxiety & 5.83 & .018 \\
Depressive & 0.72 & .399 \\
Functioning & 3.30 & .073 \\
\hline
\end{tabular}

Table 5: MANOVA for Papua

\begin{tabular}{lrl}
\hline Variable & $\mathbf{F}$ & $\mathbf{p}$ \\
\hline Time & 8.488 & .000 \\
Somatic & 30.34 & .000 \\
Anxiety & 10.45 & .002 \\
Depressive & 9.83 & .003 \\
Functioning & 6.65 & .013 \\
\hline
\end{tabular}



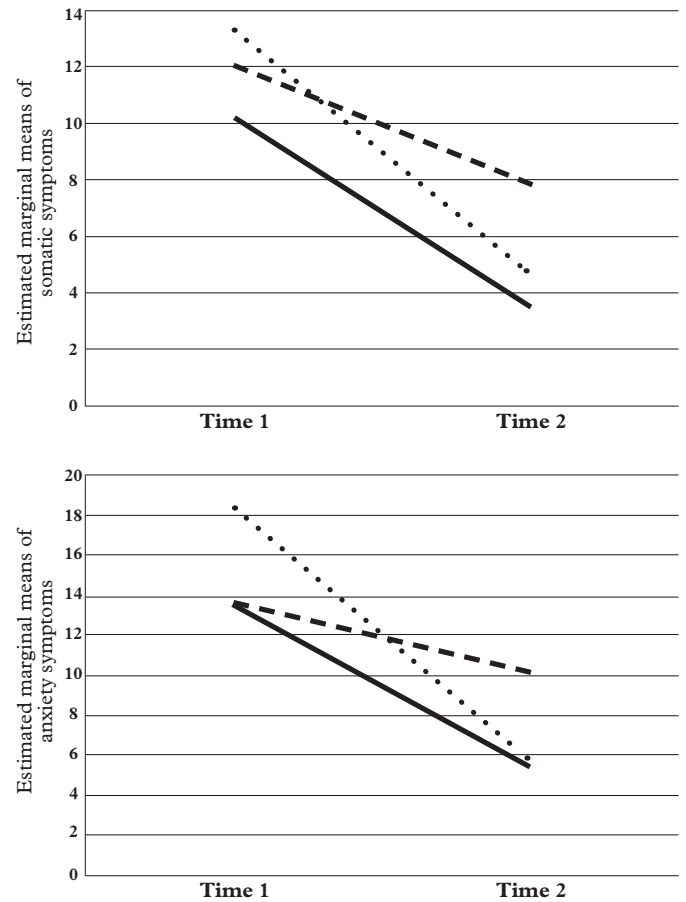

Figure 1: Graph displaying the change in somatic symptoms in the three locations from Time 1 to Time 2

$$
\begin{aligned}
& \text { - Jakarta } \\
& \text {-. Aceh } \\
& \text { - Papua }
\end{aligned}
$$

Figure 2: Graph displaying the change in anxiety symptoms in the three locations from Time 1 to Time 2

$$
\begin{aligned}
& \text { - Jakarta } \\
& \text {-. Aceh } \\
& \text { - Papua }
\end{aligned}
$$

\section{Discussion}

The results of the analyses indicated there was a significant reduction in all of the symptoms measured over time. This suggests that the supportive counseling provided by paraprofessionals was effective, as anxiety symptoms, depressive symptoms, somatic symptoms, and functioning improved from $\mathrm{T} 1$ to $\mathrm{T} 2$.

The participants in both modes of counseling, individual and group, experienced significantly improved symptom levels at T2. However, the female participants in support groups improved more than the male participants in individual therapy who were from a different region of the country.

It is difficult to parse out why the male participants in Papua did not improve as much as the female participants in Aceh and Jakarta. The difference in symptom levels at
T2 may be due to the fact that they received individual therapy, their gender, the traumatic events experienced or the nature of the conflict and culture in Papua. The severity and the length of the conflict in Papua may have led to long-term mental health difficulties for the participants. These types of symptoms are more difficult to treat and thus the rate of improvement is slower. Similarly, male participants may have had more difficulty in a therapeutic environment than female participants.

The counseling support was provided to those in need in targeted districts. With additional financial and technical support, a waitlist control trial could have been envisioned for rigorous research, but this was not the case because the funding was available for services and not for research.

The program did not have the finances to 
organize an ethical waitlist control. A waitlist control group would allow the researchers to compare the symptomatology of the participants in the intervention group with the symptomatology of the participants in the control group, and thus more definitively determine the effectiveness of the intervention. The participants in the control group would then have access to the same intervention in order to maintain the ethicality of the research. Future research would benefit from additional funding for the use of a waitlist control group or a multiple baseline design to reliably show the changes were due to the intervention.

Although there was no control group for this study due to the reasons mentioned above, the improvements in participants' symptomatology were evident. The participants in this study may have experienced
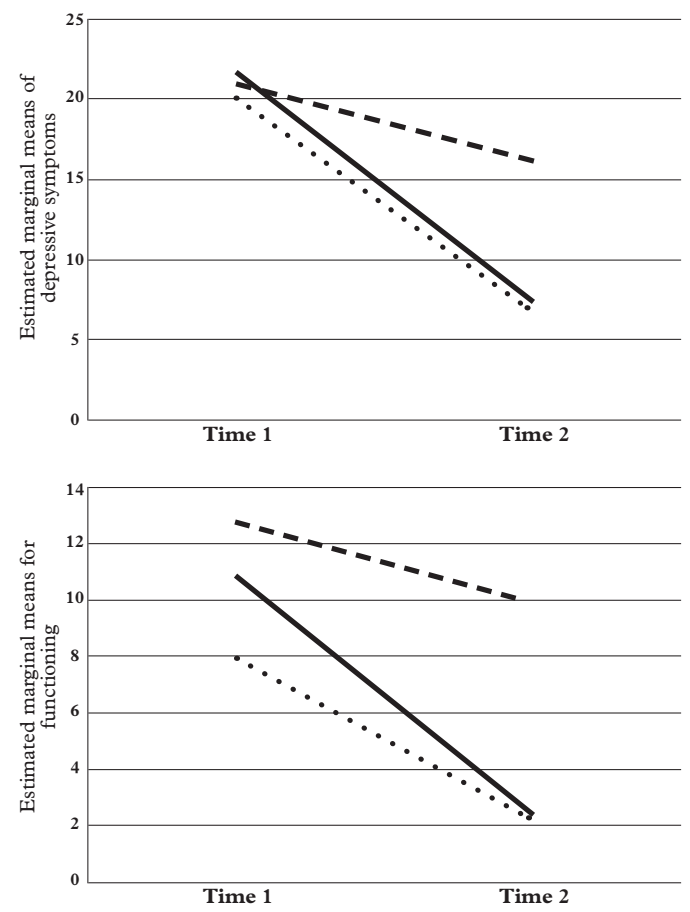

torture and victimization several years prior to the intervention, and other participants may have had more recent experiences. The physical and psychological consequences of torture tend to be chronic and lifelong, $, 8-10,15$ and it is unlikely that the participants would have significantly improved over three months without the aid of a therapeutic intervention.

This program evaluation also shows the significant impact that paraprofessionals can have on survivors of torture. Since the majority of torture incidents occur in developing countries, which do not always have professionals like psychologists or psychiatrists to provide support to the survivors, empowering local paraprofessionals to provide mental health services has been a growing trend in the humanitarian sector. This task shifting seems to be an

Figure 3: Graph displaying the change in depressive symptoms in the three locations from Time 1 to Time 2

$$
\begin{aligned}
& \text { - Jakarta } \\
& \text {.. Aceh } \\
& \text { - Papua }
\end{aligned}
$$

Figure 4: Graph displaying the change in impairment in functioning in the three locations from Time 1 to Time 2

_... Jakarta

- Papua 
avenue that is logical and needs exploration. ${ }^{29}$ The current program evaluation shows a positive outcome towards the utilization of paraprofessionals in underserved locations.

The first limitation of this study was that it was an analysis of an existing dataset. The data were collected to assess the participants' improvement throughout the course of the intervention. There was no control group and the participants could have improved as a result of time passing alone, although the improvements noted were unlikely to have occurred over three months without the aid of the intervention.

The second limitation was the confound between gender, mode of therapy and location. The confound does not allow the data from the male participants in Papua to be analyzed along with the data from female survivors in Jakarta and Aceh.

The third limitation is that participant demographics were not collected and a long-term follow up was not completed. This information cannot be used in the analysis or interpretation of the results. It is recommended that any future program evaluation

\section{References}

1. Amnesty International. Amnesty International Report 2011: The State of the World's Human Rights. London; 2011.

2. Vesti P, Kastrup M. Treatment of torture survivors: Psychosocial and Somatic Aspects. In Freedy JR, Hobfoll SE, editors. Traumatic Stress: From Theory to Practice (Plenum Series on Stress and Coping). New York: Plenum Publishing; 1995.pp. 339-363.

3. Gorman W. Refugee survivors of torture: Trauma and treatment. Professional Psychology: Research and Practice. American Psychological Association (APA); 2001;32(5):443-51.

4. Riemer JM. At the side of torture survivors: treating a terrible assault on human dignity. Graessner S, Gurris N, Pross C, editors. Baltimore, MD: The Johns Hopkins University Press; 2001. includes participant demographics and a long-term follow up of retained gains.

In conclusion, the torture survivors in this study appeared to experience symptom relief and improvement in functioning following participation in the SOT program. The male participants in Papua who received individual therapy significantly improved, though they did not improve to the same extent as the female participants who received group therapy in Jakarta and Aceh.

Utilizing paraprofessionals in mental health and psychosocial interventions appears to be an effective strategy, especially in LAMIC where professionals are scarce. The role of the professionals would thus be in building the capacity of paraprofessionals and supervising their work so that populations with the burden of mental health problems, in this case, torture survivors, can receive potentially effective care and support which otherwise would not be available to them. Future programs and research is required to establish the effectiveness of this task shifting strategy when mental health professionals are not available to provide services.

5. Elsass P. Treating Victims of Torture and Violence. NYU Press; 1997.

6. Crescenzi A, Ketzer E, van Ommeren M, Phuntsok K, Komproe I, de Jong JTVM. Effect of political imprisonment and trauma history on recent Tibetan refugees in India. J Trauma Stress. Wiley-Blackwell; 2002 Oct;15(5):369-75.

7. De Jong J, editor. Trauma, War, and Violence: Public Mental Health in Socio-Cultural Context (The Springer Series in Social/Clinical Psychology). New York: Kluwer Academic/Plenum Publishers; 2002.

8. Dross P. Survivors of politically motivated torture: A large, growing, and invisible population of crime victims. U.S. Department of Justice, Office for Victims of Crime Report. 2000 Jan p. 1-12.

9. McCullough-Zander K, Larson S. 'The Fear Is Still in Me': Caring for Survivors of Torture. 
American Journal of Nursing. Ovid Technologies (Wolters Kluwer Health); 2004;104(10):54-64.

10. Van Ommeren M, de Jong JTVM, Sharma B, Komproe I, Thapa SB, Cardeña E. Psychiatric Disorders Among Tortured Bhutanese Refugees in Nepal. Archives of General Psychiatry. American Medical Association (AMA); 2001 May 1;58(5):475.

11. Carlsson JM, Olsen DR, Mortensen EL, Kastrup M. Mental Health and Health-Related Quality of Life. The Journal of Nervous and Mental Disease. Ovid Technologies (Wolters Kluwer Health); 2006;194(10):725-31.

12. Jakupcak M, Osborne T, Michael S, Cook J, Albrizio P, McFall M. Anxiety sensitivity and depression: Mechanisms for understanding somatic complaints in veterans with posttraumatic stress disorder. Journal of Traumatic Stress. WileyBlackwell; 2006;19(4):471-9.

13. Rasmussen A, Rosenfeld B, Reeves K, Keller AS. The effects of torture-related injuries on long-term psychological distress in a Punjabi Sikh sample. Journal of Abnormal Psychology. American Psychological Association (APA); 2007;116(4):734-40.

14. Olsen DR, Montgomery E, Bøjholm S, Foldspang A. Prevalence of pain in the head, back and feet in refugees previously exposed to torture: A ten-year follow-up study. Disability and Rehabilitation. Informa UK; 2007 Jan;29(2):163-71.

15. Amris K, C. de C. Williams A. Chronic Pain in Survivors of Torture. Pain. 2007 Oct;15(7).

16. Başoğlu M, Livanou M, Crnobarić C. Torture vs Other Cruel, Inhuman, and Degrading Treatment. Archives of General Psychiatry. American Medical Association (AMA); 2007 Mar $1 ; 64(3): 277$.

17. Başoğlu M, Paker M. Severity of trauma as predictor of long-term psychological status in survivors of torture. Journal of Anxiety Disorders. Elsevier BV; 1995 Jul;9(4):339-50.

18. Stepakoff S, Hubbard J, Katoh M, Falk E, Mikulu J-B, Nkhoma P, et al. Trauma healing in refugee camps in Guinea: A psychosocial program for Liberian and Sierra Leonean survivors of torture and war. American Psychologist. American Psychological Association (APA); 2006;61(8):921-32.

19. Jaranson JM, Popkin MK, editors. Caring for victims of torture. 1st ed. Washington, DC: American Psychiatric Press; 1998.

20. Başoğlu M, Ekblad S, Bäärnhielm S, Livanou M. Cognitive-behavioral treatment of tortured asylum seekers: a case study. Journal of Anxiety Disorders. Elsevier BV; 2004 Jan;18(3):357-69.

21. Bichescu D, Neuner F, Schauer M, Elbert T.
Narrative exposure therapy for political imprisonment-related chronic posttraumatic stress disorder and depression. Behaviour Research and Therapy. Elsevier BV; 2007 Sep;45(9):2212-20.

22. Tol WA, Barbui C, Galappatti A, Silove D, Betancourt TS, Souza R, et al. Mental health and psychosocial support in humanitarian settings: linking practice and research. The Lancet. Elsevier BV; 2011 Oct;378(9802):1581-91.

23. Mental Health Atlas 2011. Geneva: World Health Organization; 2011.

24. Morris J, Lora A, McBain R, Saxena S. Global Mental Health Resources and Services: A WHO Survey of 184 Countries. Public Health Reviews. 2012;34(2):1-19.

25. Patel V. Global Mental Health: From Science to Action. Harvard Review of Psychiatry. Ovid Technologies (Wolters Kluwer Health); 2012;20(1):6-12.

26. Mollica RF, Wyshak G, Marneffe D, Khuon F, Lavelle J. Indochinese versions of the Hopkins Symptom Checklist-25: a screening instrument for the psychiatric care of refugees. American Journal of Psychiatry. American Psychiatric Publishing; 1987 Apr;144(4):497-500.

27. Lee B, Kaaya SF, Mbwambo JK, Smith-Fawzi MC, Leshabari MT. Detecting Depressive Disorder With the Hopkins Symptom Checklist-25 in Tanzania. International Journal of Social Psychiatry. SAGE Publications; 2008 Jan 1;54(1):7-20.

28. Mumford DB, Bavington JT, Bhatnagar KS, Hussain Y, Mirza S, Naraghi MM. The Bradford Somatic Inventory. A multi-ethnic inventory of somatic symptoms reported by anxious and depressed patients in Britain and the Indo-Pakistan subcontinent. The British Journal of Psychiatry. Royal College of Psychiatrists; 1991 Mar 1;158(3):379-86.

29. Van Ommeren M, Sharma B, Prasain D, Poudyal B. Addressing Human Rights Violations: A Public Mental Health Perspective on Helping Torture Survivors in Nepal. In J. d. Jong (Ed.), Trauma, War, and Violence: Public Mental Health in Sociocultural Context. Springer; 2002 259-281. 